\title{
Non-Neoplastic Finding Absent
}

National Cancer Institute

\section{Source}

National Cancer Institute. Non-Neoplastic Finding Absent. NCI Thesaurus. Code C160178.

There is no non-neoplastic finding. 